\title{
Importance of the surface treatment in the peeling strength of joints for the shoes industry
}

\author{
R MM Paiva ${ }^{2 *}$, E AS Marques ${ }^{1}$, L FM da Silva $^{1}$ and M AP Vaz ${ }^{1}$
}

\author{
* Correspondence: \\ rosa.paiva@cipade.com \\ ${ }^{2}$ CIPADE - Indústria e Investigação \\ de Produtos Adesivos, S.A., Avenida \\ 10 de Maio, 518, São João da \\ Madeira 3701-909, Portugal \\ Full list of author information is \\ available at the end of the article
}

\begin{abstract}
Background: In order to contribute to the research and development of adhesives for the shoe industry, this paper aims to analyze the peel strength of an adhesive joint with various types of surface treatments. In the shoe industry, the adhesive properties are very important to ensure the quality of manufacture of the shoe, thus, to better understand the behaviour of the adhesive joint, it is important to analyze the peel resistance in order to adjust the manufacturing process. For the execution of this work, we considered the following materials: natural leather, thermoplastic rubber (TR), polyurethane (PU) and a polyurethane non structural adhesive solvent based. This paper analyzes the influences of the application of chemical and/or physical surface treatments on substrates in the peel strength of a T joint.
\end{abstract}

Findings: It was found that certain surface treatments, depending on the substrate, are required to obtain an adhesive joint capable of satisfying the minimum required by the shoes sector.

Conclusion: The main conclusion is that adhesive joints meet the show industry requirements with the application of chemical treatments for TR and mechanical treatments for leather and PU.

Keywords: Peel strength; Adhesive joints; Footwear; Polyurethane adhesive solvent based; Thermoplastic rubber; Polyurethane; Leather

\section{Findings}

In Portugal, the footwear industry is increasingly characterized by quality, comfort and beauty of its models. Hence, there has been an increase in exports, evident over the past years. While comfort is determined by the selection of materials and the shoe design, quality is determined by the construction of the shoe, being also a reflection of the materials used and the manufacturing process of the adhesive joint [1]. For the manufacture of the adhesive joint, one must take into account the need for an adhesive capable of promoting adhesion required of select materials.

The selection of optimum adhesive for the adhesive joint is not always an easy task because the materials differ and, in many cases, the materials selected for construction of a model shoe are subjected to surface treatments, which increases the complexity of the manufacturing process but provides a better union of the materials.

For the manufacture of footwear it is necessary to take into account the following operating procedures: modeling, cutting, uppering, assembly, finishing and packaging. For the preparation of this work the most demanding adhesive joint was considered. 
The joint described in this paper is part of the assembly procedure, which adjusts the upper to the form of the shoe and proceeds to glue it to the sole. The selection of these materials will vary, depending on its mechanical properties, price and intended design, thereby determining the strength, quality and comfort desired for the final product. The upper can be on natural or synthetic leather, woven or polyvinyl chloride (PVC). The soles may be of synthetic rubber, natural rubber (NR) or leather. Synthetic rubbers commonly used in the manufacture of this component for the construction of the shoe are based on polyurethane (PU), thermoplastic polyurethane (TPU), thermoplastic rubber (TR), styrene butadiene rubber (SBR), ethyl vinyl acetate (EVA), polyamide (PA), polyvinyl chloride (PVC), polystyrene (PS) or acrylonitrile butyl styrene (ABS) [2].

For the elaboration of this work, leather was selected as the material to use in upper. For the sole, thermoplastic rubber (TR) and polyurethane (PU) were selected. The TR soles are synthesized from polymer blocks, based on butadiene and styrene. This polymer is cured under the effect of sulfur which makes the healing process irreversible. However, by heating the link is weakened and elastomers may again be subjected to a change of shape. Such an occurrence is possible because the styrenic monomers are more polar and thus more soluble than butadiene and when styrene is subjected to temperature it becomes liquid. This characteristic brings advantages, as TR can be subjected to recycling processes [3]. Additionally, these soles are characterized as being resistant to water, very flexible and resilient. They are also a cheaper material when compared with other materials that exist on the market. TR soles are usually used for making women shoes of good quality, presenting itself as a material that has a tendency to replace the EVA and PVC.

PU soles are a combination of polyol with isocyanate, although, for production it may also be necessary to apply additives, in particular catalysts and pigments. After mixing these substances, a reaction occurs which enables synthesis of the polyurethane compound. This mixture is made and then immediately subjected to injection moulding, allowing to mould a sole in the desired shape. This type of sole is characterized by its durability, high resistance to wear, light weight, abrasion-resistance, ease to pigment, good thermal insulation, good flexibility at low temperatures and excellent resistance to oils. As a thermosetting material it does not soften when exposed to heat. All these ualities allow the manufacture of good quality shoes [3]. The PU soles have wide application in sports shoes, safety shoes, men's and women footwear that require a boldest design, among others.

In the footwear industry, the most important method for joining materials is adhesive bonding. In 1906 nitrocellulose adhesives were introduced, being replaced in 1949 by polychloroprene adhesives (PCP), which due to their versatility present good results in leather bonding, textiles and other materials. In 1970 the PU adhesives are then introduced in the footwear industry. Subsequently adhesives based on styrene-isoprene-styrene (SIS), styrene-butadiene-styrene (SBS), styrene-butadiene rubber (SBR), latex, aqueous dispersions and hotmelts were used [4]. However, for the bonding of upper/soles, adhesives used are based on PCP and PU. This work discusses the PU solvent-based adhesives because they are able to bond various types of materials, regarding the application upper/soles [5].

As for the surface treatment, the TR soles chemical treatment is applied to the substrate to provide uniformity, allowing and increasing the cohesive strength of the adhesive joint [6]. This treatment allows the chemically modification of the surface to be bonded. In 
the footwear industry, the most commonly used chemical treatment is via halogenated substances. During production, PU soles are coated with a release agent to facilitate its removal from the mould and the footwear industry uses more than one treatment, starting with mechanical carding which is followed by application of a primer. On the leather based uppers, mechanical treatment is applied followed by the application of a primer. This treatment creates mechanical roughening on the substrate surface by increasing the contact area and therefore increasing the number of possible linkages in the interface between the adhesive and the substrate. In the footwear industry, the mechanical treatment is the most widely used, with the carding performed using the sandpaper [6]. The primer also works as a surface pre-treatment and consists in a polymer solution in organic solvents. This composition is related with the adhesive, but with low viscosity, forming a thin layer on the substrate. The primer, when dry, provides a very strong bond with the adhesive, requiring compatibility of the primer with the adhesive [6]. In the footwear industry, various methods are used depending on the application operation. In the case of bonding upper/sole, the method of application by brush is used.

Applying PU adhesive on the substrate and after the drying time, it forms a film which does not have any tackiness. Only when subjected to temperature is that the film of adhesive softens, acquiring the necessary tack for attaching the substrates. Next, the adhesive joint is subjected to pressure, followed by the cooling and thereafter is given the start of the curing of the adhesive [4]. Therefore, we must take into account some necessary conditions for the manufacture of adhesive joint, including the reactivation temperature, working time and pressure required to promote the desired union of substrates. The reactivation temperature and time are determined by the need to soften the adhesive film and not the sole, enabling rapid development of bond strength. When working with soles that soften at low temperatures, it is necessary the use of an adhesive to provide a low temperature required for reactivation, so it might be possible to manufacture the joint by adjusting the time required for the reactivation of the adhesive film. In the application of polyurethane adhesives based solvent the process identified in Figure 1 is considered.

In the bonding of the upper to soles, the shoe industry follows the next steps:

a) submit, if necessary, treatment of the substrate surface;

b) apply the adhesive on the upper;

c) apply the adhesive on the sole;

d) let the adhesive dry by evaporation about 5 to 10 minutes at room temperature;

e) activate the adhesive using infrared radiation (IR) from 60 to $80^{\circ} \mathrm{C}$ for 2 to 6 seconds;

f) join the upper and sole, placing in the desired position;

g) pressing for 4 to 5 seconds at a pressure of approximately 2 to 4 bar [7].

The mechanical properties considered important in the manufacture of shoes are the following: peel strength and heat resistance, properties that determine the final strength of the bond. In terms of properties, this paper focuses on the peel strength, which is intended to evaluate the mechanical behaviour of the PU adhesive solvent-based when bonding leather to TR or PU soles, while taking into 


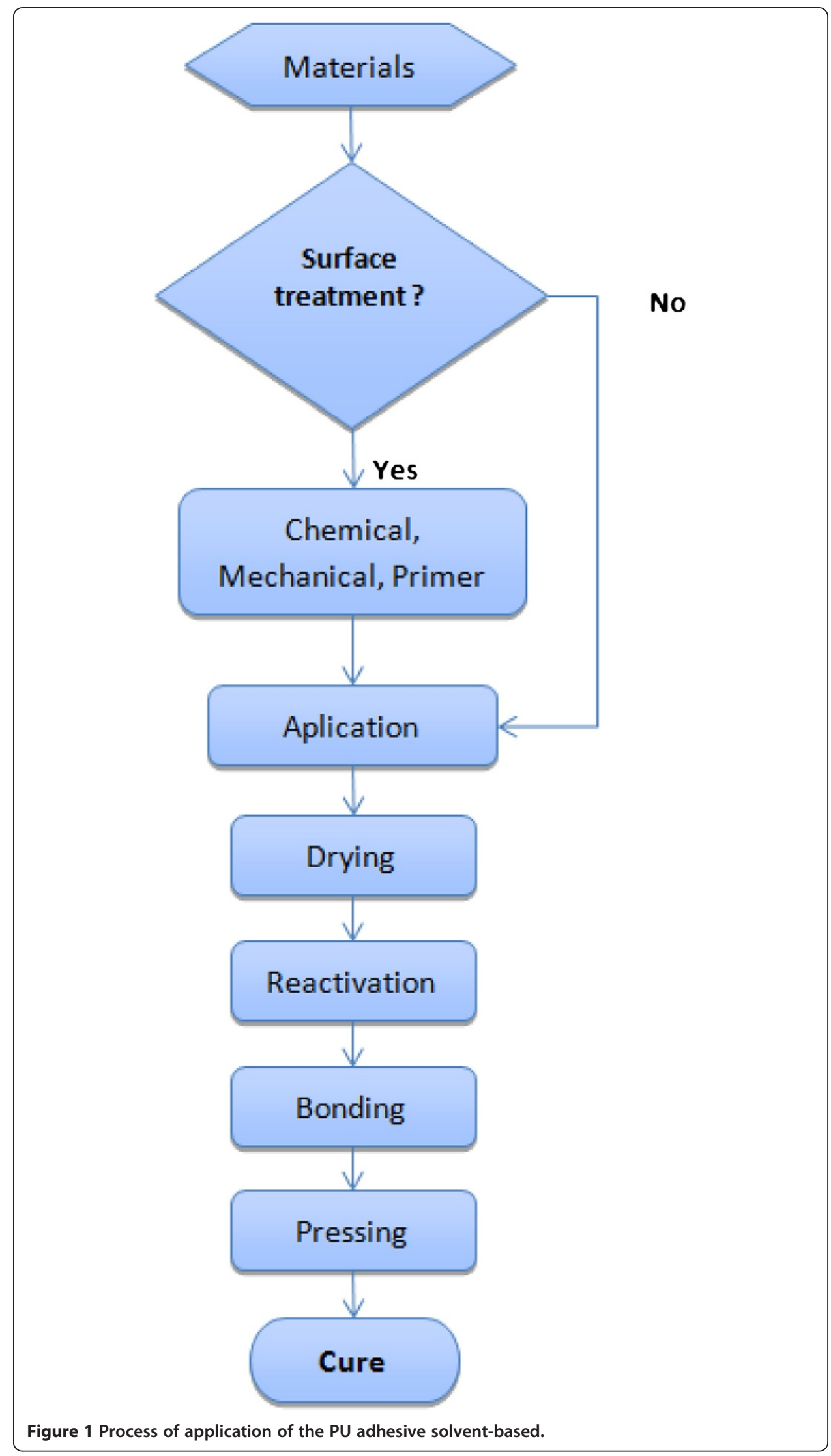


account the presence or absence of surface treatments on the substrates. The peel strength is a property which determines the strength required to peel off two materials, where at least one of the substrates is flexible; it is possible to distinguish if an adhesive is fragile or ductile.

To quantify this property the peel test was performed in a tensile testing machine, which is a standard test. Two standards are used for footwear industry adhesives:

- ISO 20344:2004 (shoe),

- EN ISO 11339:2010 (specimen) [4].

ISO 20344:2004 is designed to evaluate the bonding properties of soles where adhesion is measured by determining whether or not it is acceptable for the desired effect. This standard allows to obtain the peel strength per unit width, which is medium strength per unit width, applied by an angle between $90^{\circ}$ and $180^{\circ}$, depending on the flexibility of the substrate, in relation to joint, needed to lead to rupture. In the footwear industry independently of the type of materials used, to ensure its durability, it is necessary for adhesive joints fulfilling certain specifications defined by EN 20344 (5.2), which establishes the minimum values to consider for difficult bonding. Table 1 refers to the values required for joining upper/sole.

EN ISO 11339:2010 determines the test method for obtaining the bond strength at an angle of $180^{\circ}$, but using the materials in the form of specimen, as shown in Figure 2 [6].

\section{Experimental details}

The experimental portion of this work consisted of the analysis of peel strength in the single lap joint, subjected to tensile loading.

\section{Materials}

For the elaboration of this work, TR was considered as the reference TTSC TR-2531$80 \mathrm{C}$ (LINOS - Componentes para calçado, L.A.). In Table 2 it is possible to verify the characteristics of this material, information provided by the manufacturer of the sole (technical datasheet of the material).

The PU selected was Flexsol 486 (Flexsol - Indústria de PU, Ltd.). In Table 3 it is possible to verify the characteristics of PU used in this work, this information is provided by the manufacturer of the sole (technical datasheet of the material).

As halogenate for TR, Halinov 2190 was used (CIPADE - Indústria e Investigação de Produtos Adesivos, S.A.). As a primer for PU, Plastik 6109 (CIPADE - Indústria e Investigação de Produtos Adesivos, S.A.) was used, and as a primer for the leather the Plastik 6271 was selected (CIPADE - Indústria e Investigação de Produtos Adesivos, S.A.).

The two combinations of adherent materials under study were leather/TR and leather/ PU. Plastik 6275 (CIPADE - Indústria e Investigação de Produtos Adesivos, S.A.), a solvent

Table 1 Reference values of adhesion upper/soles, according to standard EN 20344

\begin{tabular}{cc}
\hline Shoes & Peel strength per unit width (upper/sole) \\
\hline Baby & $\geq 2 \mathrm{~N} / \mathrm{mm}$ \\
Child & $\geq 4 \mathrm{~N} / \mathrm{mm}$ \\
Woman & $\geq 3 \mathrm{~N} / \mathrm{mm}$ \\
Man & $\geq 4 \mathrm{~N} / \mathrm{mm}$ \\
\hline
\end{tabular}




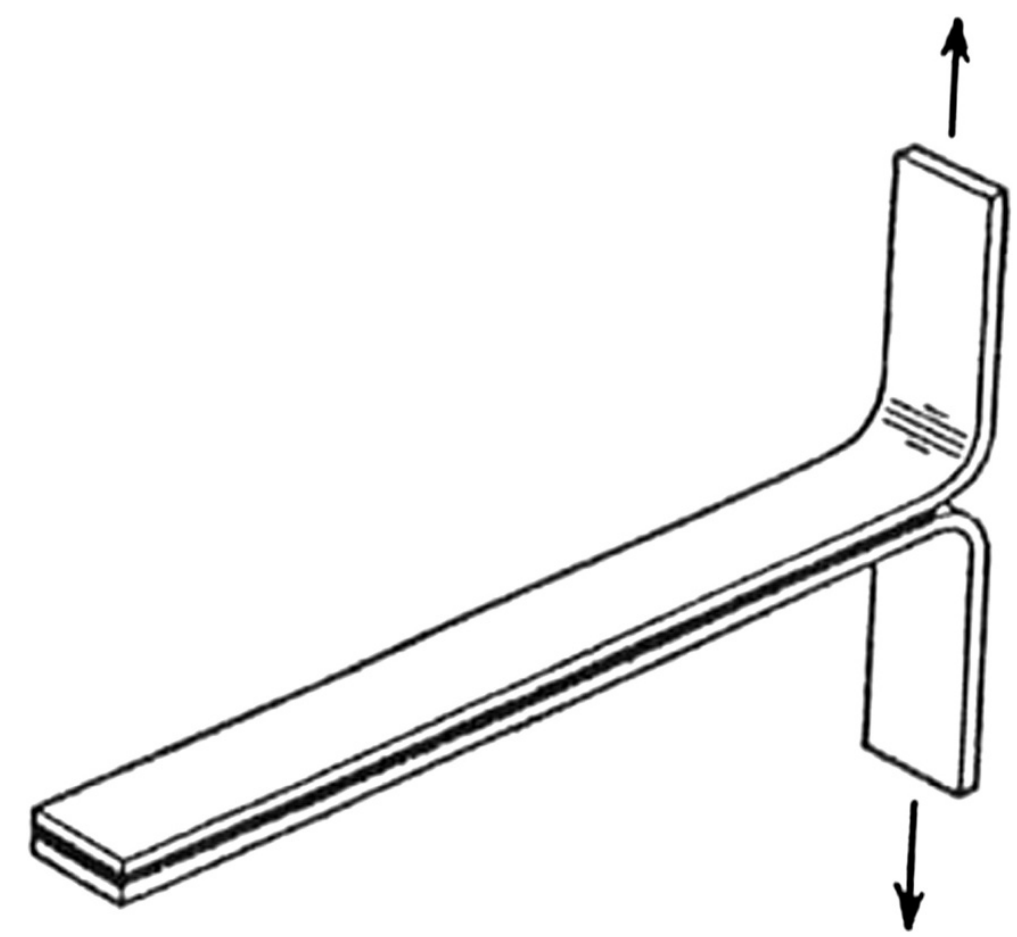

Figure 2 Adhesive joint for peel test.

based PU was used as the adhesive, which has a sufficient viscosity for the effective wetting, and is able to penetrate into the cavities created by the mechanical treatment on the substrate. Table 4 shows the characteristics of the primers and the adhesive used. These values were supplied by the manufacturer (technical datasheet of the products).

\section{Geometry}

In this work, for the manufacture of the joint, it was decided not to study the full sole and upper combination, but instead smaller peel specimens were manufactured.

The adhesive joint studied is composed of two substrates $(150 \mathrm{~mm} \times 30 \mathrm{~mm})$ glued together in an area of $100 \mathrm{~mm} \times 30 \mathrm{~mm}$, as shown in Figure 3 .

\section{Surface treatments}

For the application of surface treatment one must take into account the materials which are intended to be bonded. This work took into account the following points:

Table 2 Characteristics of the TR

\begin{tabular}{lccc}
\hline Characteristics & Method & Units & Sonaflex TTSC-2531-80C \\
\hline Density & ASTM D792 & $\mathrm{g} / \mathrm{cm}^{3}$ & $0.92-0.98$ \\
Hardness & DIN 53505 & Shore A & $77-83$ \\
Tensile & DIN 53504 & $\mathrm{MPa}$ & $\geq 4$ \\
Elongation at rupture & DIN 53504 & $\%$ & $\geq 300$ \\
Abrasion resistance & DIN 53516 & $\mathrm{mm}$ & $\leq 250$ \\
Flexion resistance & BS 5131:2.1 (150000 cycles) & $\mathrm{mm} / \mathrm{Kc}$ & $<0.1$ \\
\hline
\end{tabular}


Table 3 Characteristics of the PU

\begin{tabular}{lccc}
\hline Characteristics & Method & Units & PU 486 \\
\hline Density & DIN 53420 & $\mathrm{~g} / \mathrm{cm}^{3}$ & 0.55 \\
Hardness & DIN 53505 & Shore A & 57 \\
Tensile & DIN 53504 & $\mathrm{MPa}$ & 4.8 \\
Elongation at rupture & DIN 53504 & $\%$ & 457 \\
Abrasion resistance & DIN 53516 & $\mathrm{~mm}$ & 298 \\
Tear strength & DIN 53507 & cycles & 8.9 \\
Flex fatigue resistance & DIN 53543 & & 100.000 \\
\hline
\end{tabular}

- Variables for the surface treatment of leather

a. The leather substrates were subjected to a mechanical treatment;

b. The primer (Plastik 6271) was applied and allowed to dry for 5 to 20 minutes at room temperature;

- Variables for the surface treatment of PU

a. The PU substrates were subjected to a mechanical treatment;

b. The primer (Plastik 6109) was applied and allowed to dry about 1 hour at room temperature;

- Variables for TR surface treatment

a. The TR substrate was subjected to chemical treatment (2190 Halinov) and allowed to dry at least 1 hour at room temperature;

- Procedure for the manufacture of single lap joint

a. The adhesive, Plastik 6275 , was applied in both substrates and allowed to dry for 10 to 15 minutes at room temperature;

b. The adhesive films were activated by IR radiation at about $70^{\circ} \mathrm{C}$ for 6 seconds;

c. The substrates, leather/TR and leather/PU, were bonded in the desired position, as seen in Figure 3;

d. The adhesive joint was subjected to 2 to 4 bar of pressure for 4 to 5 seconds.

For the mechanical treatment a P24 aluminium oxide abrasive cloth was used.

Table 4 Characteristics of the primers and adhesive

\begin{tabular}{lcccc}
\hline Characteristics & Units & Plastik 6275 & Plastik 6271 & Plastik 6109 \\
\hline Viscosity & $\mathrm{CPs}$ & $3500-4000$ & $250-300$ & $100-200$ \\
Solids & $\%$ & $15-19$ & $18-21$ & $6-10$ \\
Density & $\mathrm{g} / \mathrm{cm}^{3}$ & $0.82-0.88$ & $0.85-0.91$ & $0.83-0.89$ \\
Drying time & $\mathrm{min}$ & $10-15$ & $5-20$ & 60 \\
Reactivation temperate & ${ }^{\circ} \mathrm{C}$ & 70 & - & - \\
\hline
\end{tabular}




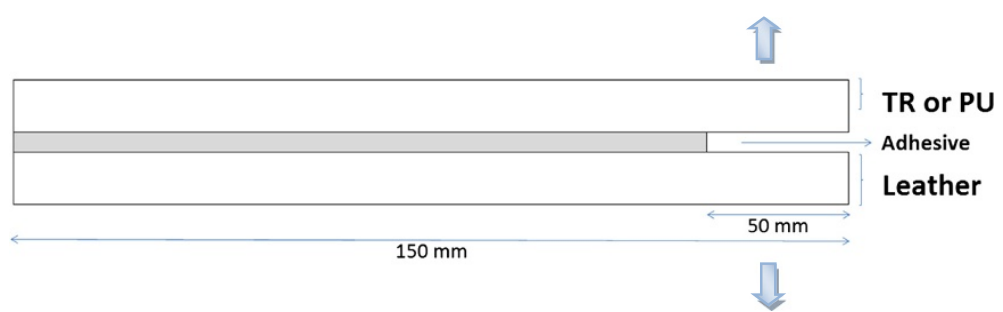

Figure 3 Test piece geometry.

The adhesive joints, after being pressed, were stored in standard conditions $\left(23^{\circ} \mathrm{C}, 50 \% \mathrm{Hr}\right)$ during $24 \mathrm{~h}$, in order to ensure the complete cure of the adhesive. Only then they were subjected to the peel test.

\section{Peel test}

In the production of the adhesive joints, taking into account the material under study, the surface treatments were considered as variables, in order to be able to identify their importance in the peel strength. Therefore, the first step was making an application of all treatments commonly used in the footwear industry, followed by the manufacture of an adhesive joint without any surface treatment. In addition, joints were fabricated where only one of the treatments was performed. Other combinations were done in order to examine the effect of treatments. For the preparation of this work, for leather/ TR joints, the test plan identified in Table 5 was followed.

In the manufacture of leather/PU joints, since the manufacture of adhesive joints leather/TR had already tested the influence of surface treatments on leather, only treatments on PU were selected as variables, as shown in the test plan of Table 6.

24 hours after the manufacture of the adhesive joint, the peel test was performed in the testing machine at a speed of $50 \mathrm{~mm} / \mathrm{min}$. The results are expressed as load (N) versus extension $(\mathrm{mm})$. The peel strength per unit of width is determined by the ratio between the maximum force and the width of the overlap joint. Three adhesive joint specimens for each test were considered. An image of the mechanical system used to obtain the peel strength is shown in Figure 4.

The traction machine used is an Instron, model 3367, with load cell of $30 \mathrm{kN}$.

\section{Results}

On Figure 5 are represented the load displacement curves for different surface treatments of the adhesive joints using leather/TR.

Maximum strength values and standard deviation associated with each test are shown in Figure 6.

Additional file 1: Table S1 shows the different types of failure identified on the tested joints, divided according to their treatment.

Table 5 Test plan for specimens leather/TR

\begin{tabular}{lllllllll}
\hline Mat. & Surface treatment & $\mathbf{1}$ & $\mathbf{2}$ & $\mathbf{3}$ & $\mathbf{4}$ & $\mathbf{5}$ & $\mathbf{6}$ & $\mathbf{7}$ \\
\hline TR & Chemical & $\times$ & & $\times$ & & $\times$ & & \\
Leather & Mechanical & $\times$ & & & $\times$ & $\times$ & & $\times$ \\
& Primer & $\times$ & & & & & $\times$ & $\times$ \\
\hline
\end{tabular}


Table 6 Test plan for specimens leather/PU

\begin{tabular}{llllll}
\hline Mat. & Surface treatment & $\mathbf{1}$ & $\mathbf{2}$ & $\mathbf{3}$ & $\mathbf{4}$ \\
\hline PU & Mechanical & $\times$ & & $\times$ & \\
& Primer & $\times$ & & & $\times$ \\
Leather & Mechanical & $\times$ & $\times$ & $\times$ & $\times$ \\
& Primer & $\times$ & $\times$ & $\times$ & $\times$ \\
\hline
\end{tabular}

Figure 5 shows that the application of all treatments, namely, on TR the chemical treatment and on leather the application of mechanical treatment and primer, conferred a higher peel strength, were rupture occurs on TR, as shown in the figure a) presented in Additional file 1: Table S1.

However, as the force increases, at some point TR deformation occurs, and the adhesive joint is not effectively tested, being measured only the elongation of the material, as shown in Figure 7.

In the absence of chemical treatment on TR, the adhesive joint breaks on the interface adhesive/TR as shown in Figures d) and g) of Additional file 1: Table S1. In the absence of mechanical treatment on the leather, the adhesive joint breaks by the interface between adhesive and leather, as shown in Figures b), c) and e) of Additional file 1: Table S1. When treatment is not applied, the leather/TR adhesive joint behaves in the same way as when only the primer is applied on the leather, or only the chemical treatment on TR, that is, the rupture of the joint occurs by the interface between adhesive and leather.

The application of the chemical treatment on TR promotes anchoring of the adhesive, as shown in Figure 8.

Figure 9 shows the load displacement curves in peel testing for various surface treatments for leather/PU adhesive joints.

The maximum strength values and respective standard deviation are shown in Figure 10.

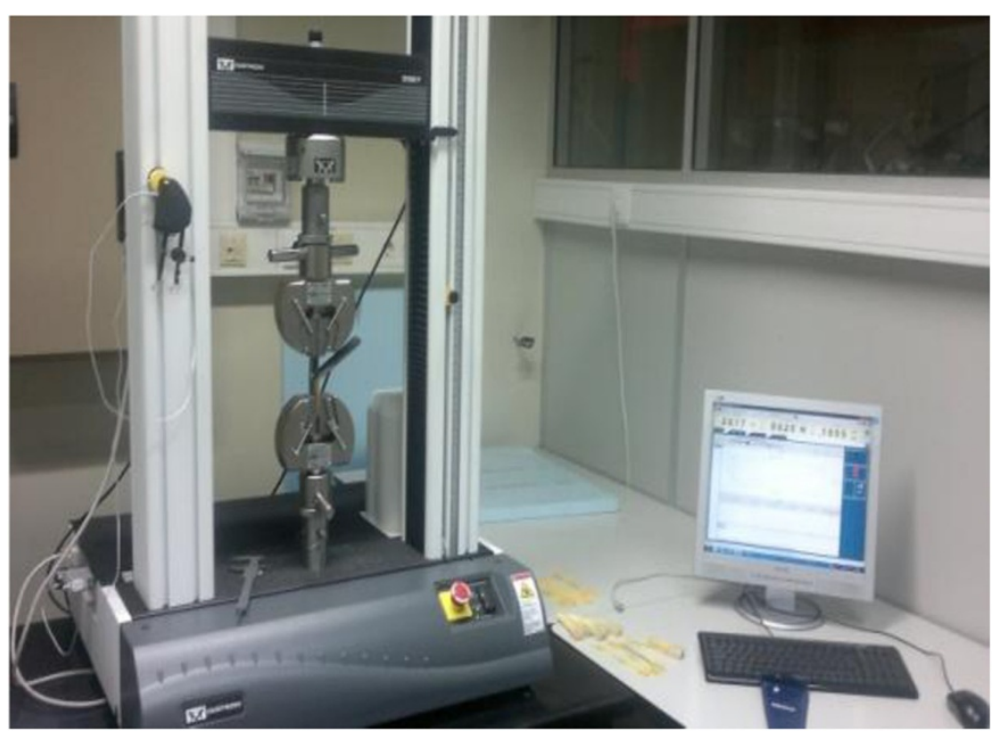

Figure 4 Testing machine and mounting system. 


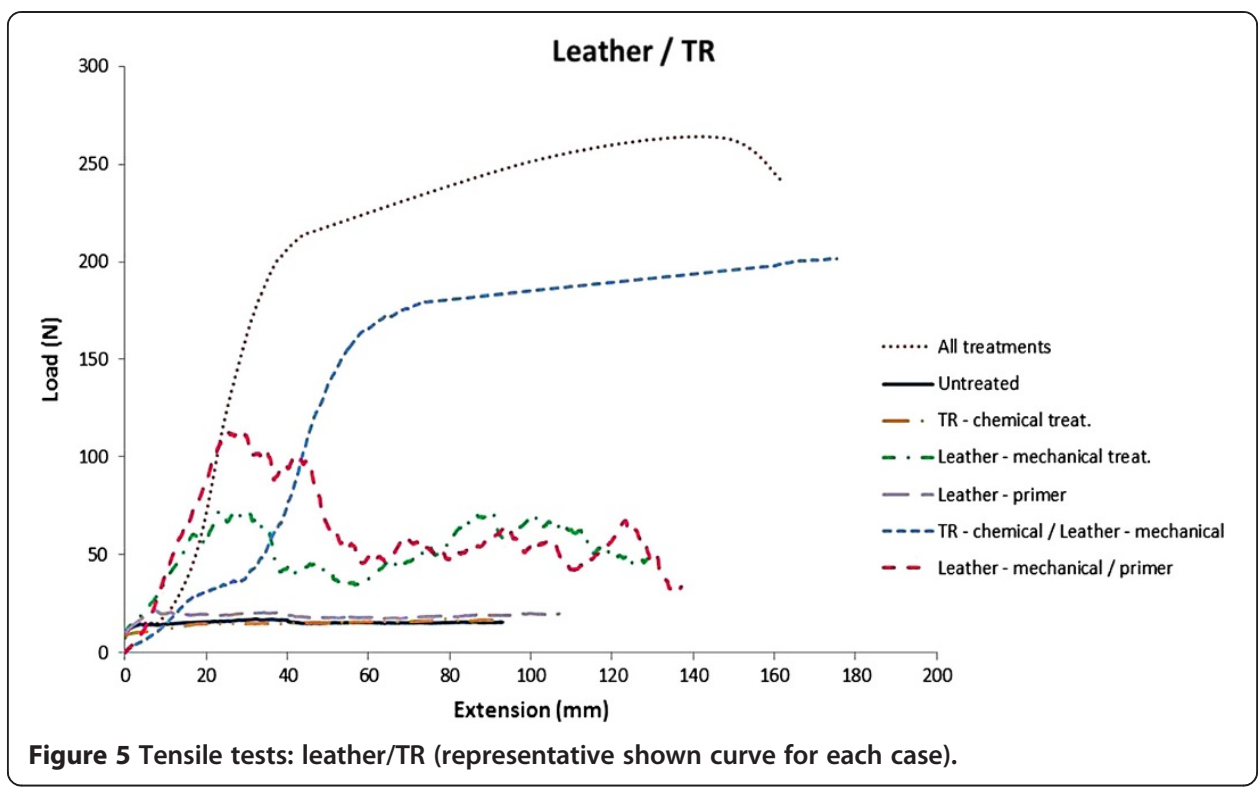

In Additional file 2: Table S2 are identified the types of failure surface of the PU joints, according to their surface treatments.

Figure 9 shows that when all surface treatments are applied to PU, the rupture at the joint occurs on the PU, and the same was verified when mechanical treatment was applied as shown in Figures a) and c) of Additional file 2: Table S2.

When surface treatments are not applied, the rupture occurs through the joint interface between adhesive and PU, and the same is verified when only primer is applied as surface treatment. This is shown in Figures b) and d), respectively.

\section{Discussion}

With the development of this work it was found that the application of all surface treatments on leather/TR adhesive joint provides the highest failure strength in the peel test. Taking into account that the leather has a surface with low surface tension, if mechanical treatment is not applied, the application of chemical treatment on the TR does not cause any improvement in the joint strength and rupture occurs by the

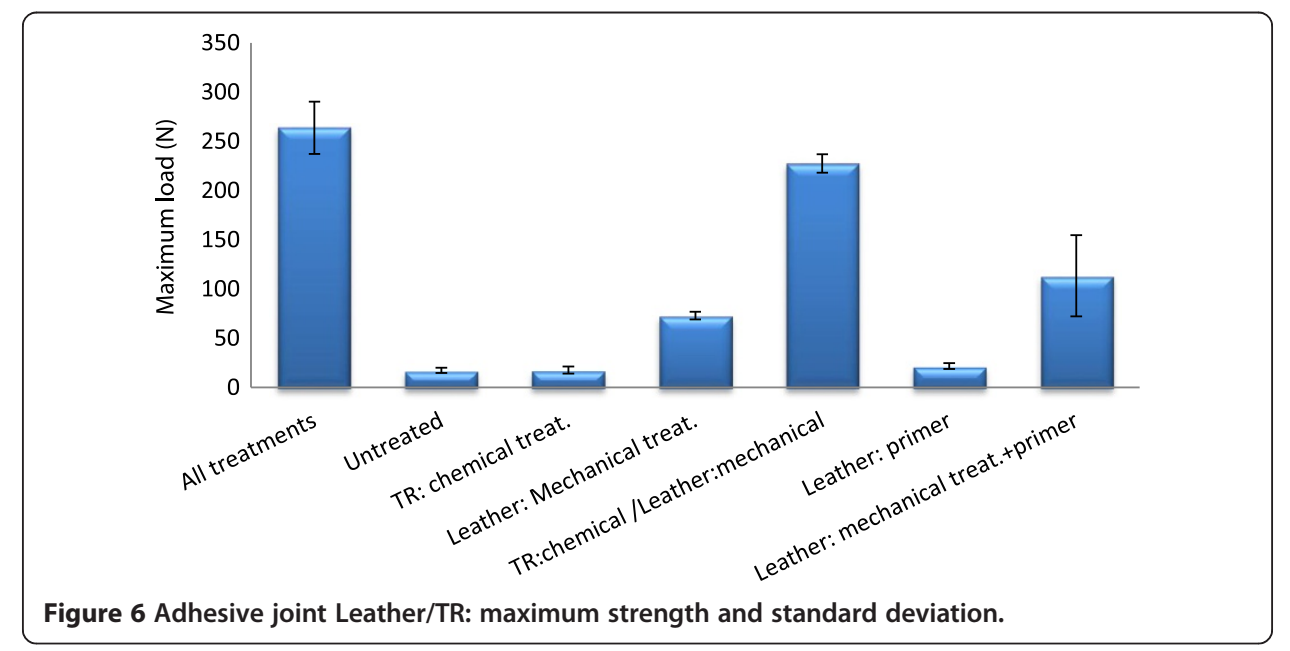




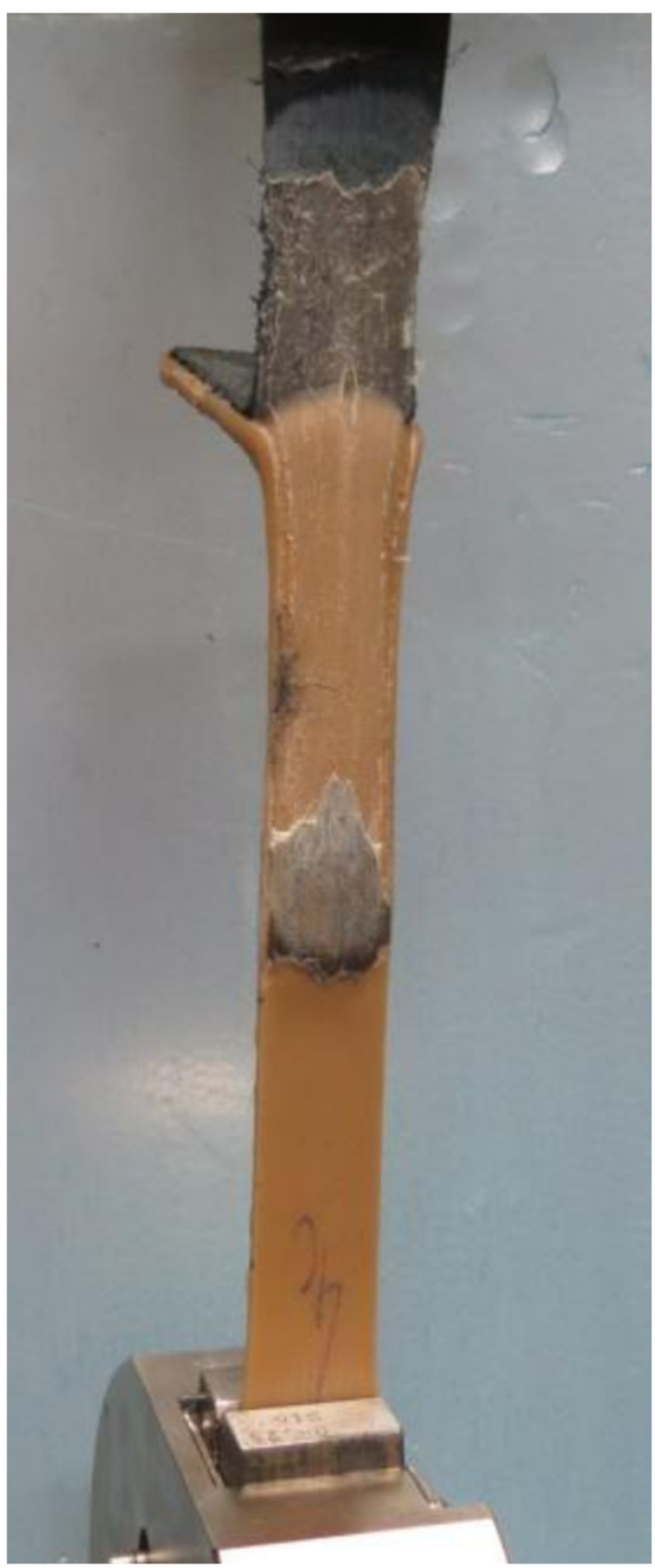

Figure 7 Specimens leather/TR: with deformation of the TR. 


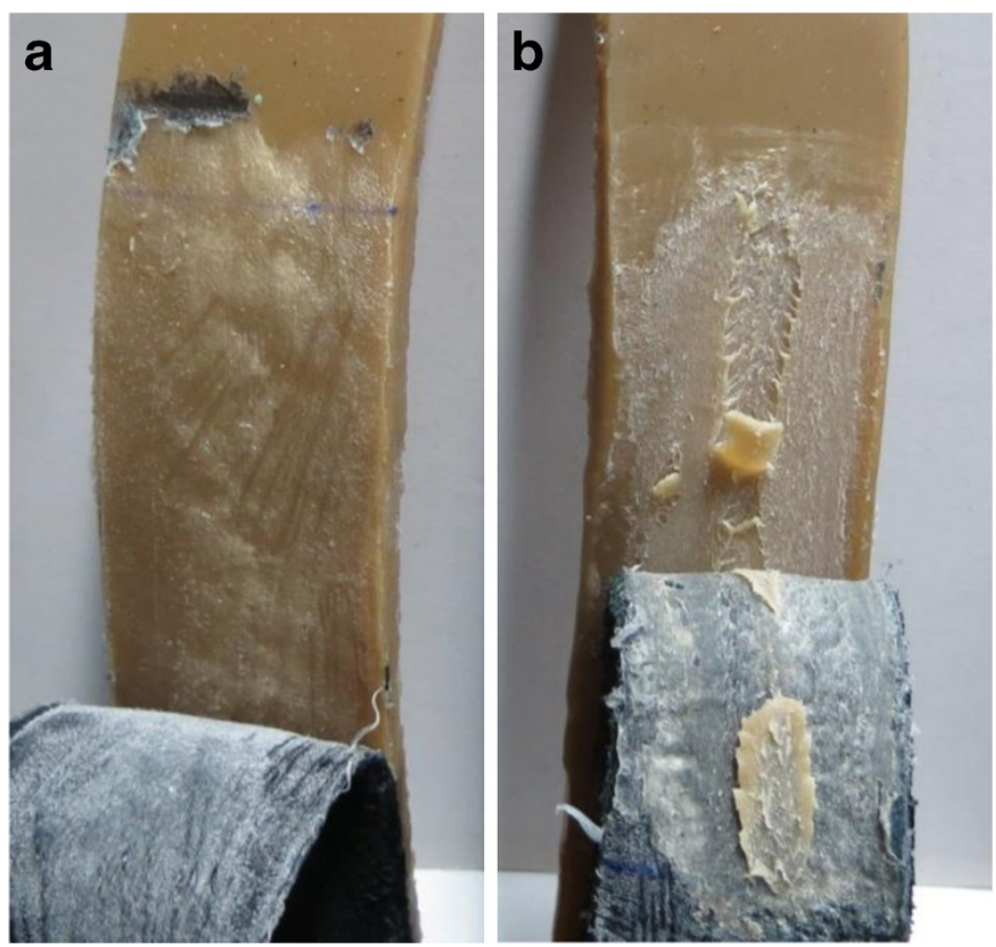

Figure 8 Specimens leather/TR. a) without chemical treatment on the TR. b) with chemical treatment on TR.

surface layer of the leather. That is, rupture occurs by the interface adhesive/leather. Considering the leather/TR, if only a mechanical treatment is applied on the leather, it is possible to obtain an increase of the peel strength. The primer on the leather works as a reinforcement. The mechanical treatment allows the anchoring of the adhesive and will decrease the thickness of the leather. When primer and mechanical treatment are combined, the peel strength of an adhesive joint is increased.

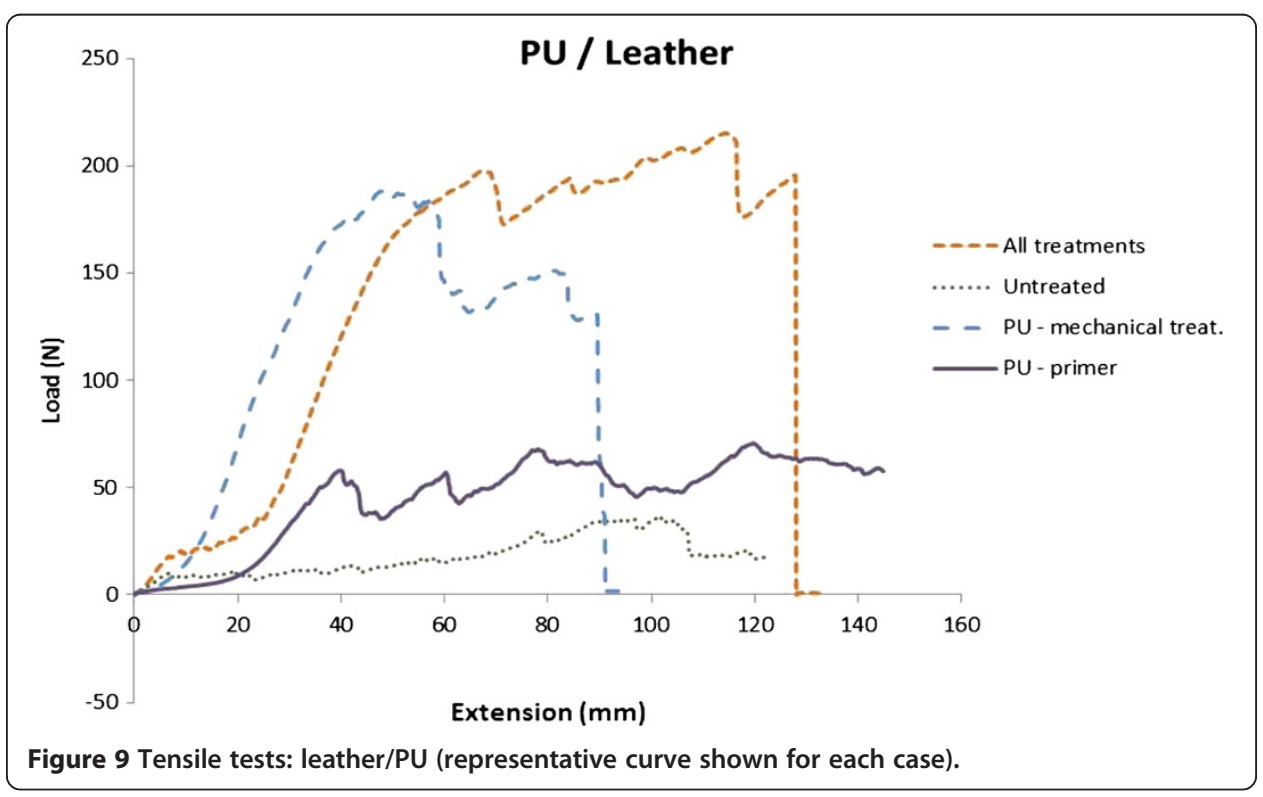




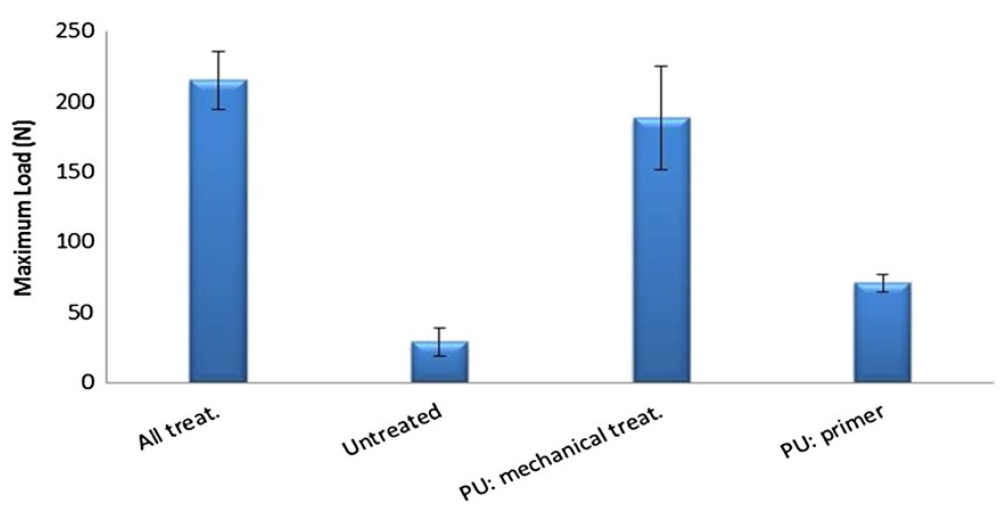

Figure 10 Adhesive joint leather/PU: maximum force (N) and standard deviation.

When applying the chemical treatment on the TR, there is a better anchoring of the adhesive, leading to a more uniform behaviour of the joint. Applying chemical treatment on the TR and mechanical treatment on the leather, allows the adhesive joint to show high values of peel strength, very close to the values obtained when all surface treatments are applied. Since the sample is $30 \mathrm{~mm}$ wide and considering the maximum peel strength identified in Figure 6, peel strength per unit width of each adhesive joint was determined and is shown in Table 7.

Comparing the values determined in Table 7 and minimum values defined by the standard EN 20344 (5.2), as shown in Table 1, it was found that to obtain conform results for bonding baby shoes it is necessary to apply mechanical treatment on the leather. In women's footwear, in addition to the mechanical treatment, the primer must be applied on the leather. In the men's and children footwear, it is necessary to apply the mechanical treatment in the leather and chemical treatment on the TR. The maximum strength for this case is obtained when applied also at the leather the primer.

In the PU, if only the mechanical treatment is applied, the peel values obtained are high. However, the same cannot be said with if only the primer is applied on PU. Table 8 shows values of the peel strength per unit width of the joint leather/PU.

Comparing the values of Table 8 and the minimum values defined by the standard EN 20344 (5.2), as shown in Table 1, it was found that to obtain conform results of bonding, for baby shoes it is necessary to apply mechanical treatment on the leather and on PU the primer or mechanical treatment can be applied. In the men's women

Table 7 Adhesive joint leather/TR: peel strength per unit width

\begin{tabular}{lcc}
\hline Surface treatments & Maximum load (N) & Peel strength per unit width (N/mm) \\
\hline All treatments & 264 & 8.80 \\
Untreated & 17.3 & 0.58 \\
TR: chemical treatment & 17.5 & 0.58 \\
Leather: mechanical treatment & 73 & 2.43 \\
TR: chemical/Leather: mechan. & 227 & 7.57 \\
Leather: primer & 22 & 0.73 \\
Leather: mechan. + primer & 113 & 3.77 \\
\hline
\end{tabular}


Table 8 Adhesive joint leather/PU: peel strength per unit width

\begin{tabular}{lcc}
\hline Surface treatments & Maximum load $(\mathbf{N})$ & Peel strength per unit width (N/mm) \\
\hline All treatments & 215 & 7.17 \\
Untreated & 29 & 0.97 \\
PU: mechanical treatment & 188 & 6.27 \\
PU: primer & 71 & 2.37 \\
\hline
\end{tabular}

and children footwear, it is necessary to apply the mechanical treatment and primer on leather. On PU the mechanical treatment must be applied, with the maximum strength being obtained when the primer is also applied.

\section{Conclusions}

The information obtained in this work allows determining the influence of surface treatments for the manufacture of leather/TR and leather/PU adhesive joints.

It can be concluded that to maximize peel strength of the leather/TR and leather/PU joints it is necessary to apply as surface treatment:

$>$ on TR - chemical treatment,

$>$ on leather - mechanical treatment and primer,

$>$ on PU - mechanical treatment and primer.

However, considering the most demanding footwear, adhesive joints already meet the requirements defined by EN 20344 (5.2) with the application of surface treatments:

$>$ on TR - chemical treatment,

$>$ on leather - mechanical treatment,

$>$ on PU - mechanical treatment.

These conclusions allow manufacturers of footwear to minimize the number of operations in the manufacture of shoes, while still being capable of satisfying the minimum requirements for the sector.

Competing interests

The authors declare that they have no competing interests.

Authors' contributions

R MM Paiva carried out the surface treatements and manufactured the joints. E AS Marques tested the adhesive joints.

L FM da Silva and M AP Vaz acted as supervisors. All authors read and approved the final manuscript.

Acknowledgements

To the companies CIPADE, LINOS and Flexsol, the authors gratefully acknowledge the provision of materials required for the manufacture of adhesive joints.

Author details

${ }^{1}$ Departamento de Engenharia Mecânica, Faculdade de Engenharia, Universidade do Porto, Rua Dr. Roberto Frias, Porto 4200-465, Portugal. ${ }^{2}$ CIPADE - Indústria e Investigação de Produtos Adesivos, S.A., Avenida $1{ }^{\circ}$ de Maio, 518, São João da Madeira 3701-909, Portugal.

Received: 13 August 2013 Accepted: 1 October 2013

Published: 23 December 2013 


\section{Additional files}

Additional file 1: Table S1. Adhesive joint leather/TR: types of failure of the peel tests.

Additional file 2: Table S2. Adhesive joint leather/PU: types of failure of the peel tests.

\section{References}

1. Yue D, Yue C (1997) Shoes - their history in words and pictres. Houghton Mifflin, Boston

2. Falco APS (2007) Avaliação da Adesivos utilizados em solados de calçado de uso Marinha do Brasil, para obtenção do Grau Mestre em Ciências em Engenharia Metalúrgica e de Materiais

3. Wegman RF (1989) Surface preparation techniques for adhesives bonding. Noyes Publications, UK

4. Karmann W, Gierenz G (2001) Adhesives and adhesive tapes. Wiley-VCH, Hamburg

5. Pizzi A, Mittal KL (2003) Handbook of adhesives technology. $2^{a}$ edição, Marcel Dekker Inc, USA

6. Silva LFM, Magalhães AG, Moura MFSF (2007) Juntas adesivas estruturais. Publindústria, Porto

7. Silva LFM, Ochsner A, Adams RD (2011) Handbook of adhesion technology. Volume I e II, Springer-Verlag, cop, Berlin

doi:10.1186/2196-4351-1-5

Cite this article as: Paiva et al: Importance of the surface treatment in the peeling strength of joints for the shoes industry. Applied Adhesion Science 2013 1:5.

Submit your manuscript to a SpringerOpen ${ }^{\odot}$ journal and benefit from:

- Convenient online submission

- Rigorous peer review

- Immediate publication on acceptance

- Open access: articles freely available online

- High visibility within the field

- Retaining the copyright to your article

Submit your next manuscript at $>$ springeropen.com 